\title{
Compliance with antenatal screening for hepatitis B surface antigen carrier status in pregnant women and consecutive procedures in exposed newborns
}

Received: 29 April 2004/ Revised: 5 July 2004/ Accepted: 6 July 2004/Published online: 17 August 2004

(C) Springer-Verlag 2004

\begin{abstract}
The goal of this study was to determine compliance with official recommendations for prevention of perinatal hepatitis B virus transmission from hepatitis B surface antigen (HBsAg) positive mothers to their offspring. All infants born to HBsAg positive mothers at the University Women's Hospital in Basel, Switzerland, in 2001 were identified and post-exposure immunisations were analysed. In addition, detailed written information on subsequent hepatitis B immunisations was obtained from the infants' paediatricians. A total of 1513 women gave birth to 1554 children and screening for $\mathrm{HBsAg}$ had been performed in $1503(99 \%)$ ) women, of whom $8 \%$ were screened during delivery. A group of $18(1.2 \%)$ women were $\mathrm{HBsAg}$ positive and $17(95 \%)$ of the 19 exposed infants promptly received active and passive immunisation. One exposed infant was lost to follow-up and in one, postnatal vaccination was missed. Of the remaining 17 exposed infants, $9(53 \%)$ received the full course of three active immunisations, but only two $(12 \%)$ were immunised within the recommended time frame. On follow-up, six children were still too young for serological testing for successful immunisation. Among the remaining 11 immunised infants, serological testing had been performed in $4(36 \%)$. Conclusion: Compliance with recommendations for hepatitis B surface antigen screening was excellent in this study. The proportion of exposed infants receiving all three active immunisations was satisfactory, but more
\end{abstract}

This work forms the medical thesis of Kirsten Beckers undertaken in the Medical Faculty, University of Basel, Switzerland.

\section{K. Beckers}

Department of Internal Medicine,

Spital Zofingen, Zofingen,

Switzerland

U. B. Schaad · U. Heininger $(\bowtie)$

University Children's Hospital (UKBB),

PO Box, 4005 Basel, Switzerland

E-mail: Ulrich.Heininger@unibas.ch

Tel.: + 41-61-6856565

Fax: + 41-61-6856012 attention must be paid to complete and timely administration and serological testing in the future. This will require improved communication between neonatology units and care-providing paediatricians in private practices.

Keywords HBsAg screening · Hepatitis B - Infants · Pregnancy $\cdot$ Vaccination

Abbreviations $\mathrm{HBeAg}$ : hepatitis B envelope antigen . HBsAg: hepatitis B surface antigen - HBIG: hepatitis B immunoglobulin $\cdot \mathrm{HBV}$ : hepatitis B vaccine

\section{Introduction}

An estimated 2 billion people world wide are infected with the hepatitis B virus, of whom 350 million suffer from chronic disease [11]. About $25 \%$ of chronically ill patients will develop progressive liver disease with cirrhosis and an additional risk of hepatocellular carcinoma [16]. Furthermore, about one million people die every year from sequelae of chronic hepatitis. The frequency of hepatitis B surface antigen (HBsAg) carriers in Switzerland is estimated to be $0.3 \%(0.5 \%$ in women of child-bearing age) which equals a prevalence of approximately 20000 individuals with chronic disease $[3,12]$.

The risk of vertical transmission of hepatitis B virus during birth and the subsequent development of chronic disease is approximately $90 \%$ in untreated offspring of $\mathrm{HBsAg}$ and hepatitis $\mathrm{B}$ envelope antigen ( $\mathrm{HBeAg}$ ) positive mothers [2] and $40 \%$ in those born to $\mathrm{HBsAg}$ positive, $\mathrm{HBeAg}$ negative mothers [13]. In light of this significant morbidity, the Swiss Federal Health Office has recommended antenatal hepatitis B screening for all pregnant women followed by active and passive immunisation of all infants born to HBsAg positive mothers since 1997 [3]. If screening has not been performed before birth, an emergency screening test should take place during or shortly after birth. The objective is to 
identify those infants in need for immunoprophylaxis as soon as possible (preferable within $12 \mathrm{~h}$ ) in order to prevent infection. This procedure has a success rate of $90 \%-97 \%$ and also provides long-lasting immunity $[6,7]$. For completion of the immunisation series, two further doses of hepatitis B vaccine (HBV) are recommended at 1 and 6 months of age. Supplementary serological control of successful immunisation of the infant is recommended at the age of 9-15 months as an aid in the long-term medical management of the few vaccine failures in patients who become infected.

The goal of the present study was to determine compliance with official recommendations to prevent perinatal hepatitis B transmission in infants born at the University Women's Hospital in Basel, Switzerland.

\section{Subjects and methods}

Data collection

In this retrospective study, records of all women admitted for delivery to the University Women's Hospital in Basel between January 1 and December 31, 2001, were identified. The following data were extracted from the patient records: mother and child's date of birth, maternal nationality and $\mathrm{HBsAg}$ status. Additional demographic information was collected if the mother was HBsAg positive: full names of mother and child, address and home phone number (if available), and name of the paediatrician selected for further care. Moreover, the exact time interval of administration of hepatitis B immunoglobulin (HBIG) and/or HBV after birth was assessed. The child's discharge letter was evaluated for specific details on the HBsAg positive status of the mother, immunisation procedures while in hospital, and recommendations regarding the need for completion of the immunisation series as well as subsequent serological monitoring.

Informed consent was obtained from all HBsAg positive mothers to contact their child's paediatrician. Then, a standardised questionnaire was sent to the paediatricians to obtain information on number and dates of any subsequent hepatitis B immunisations in the individual children and results of subsequent serological monitoring.

This investigation was approved by the ethics committee of the University of Basel Medical Faculty.

\section{Data analysis}

In accordance with the Swiss national guidelines for prevention of hepatitis B in newborns of HBsAg positive mothers [3], parameters assessed were categorised as "complete and on time" if: HBIG was administered within the first $12 \mathrm{~h}$ of birth and a first dose of HBV was administered within $12 \mathrm{~h}$ and was followed by a second dose of HBV at 4 (-6) weeks of age and a third dose of HBV at 6 months of age (+/-2 weeks). Alternatively, if the interval between the second and third immunisation was less than 2 months, a fourth dose of HBV was necessary (0-1-2-12 month schedule). Furthermore, a serum sample was to be taken at 9-15 months of age to determine the level of anti-HBs antibodies and to exclude chronic infection by determining the HBsAg status of the child. An anti-HBs antibody level of $\geq 100 \mathrm{mIU} /$ $\mathrm{ml}$ is considered to correlate with long-term protection from hepatitis B. In the case of anti-HBs levels $<100 \mathrm{mIU} / \mathrm{ml}$, further dose(s) of active immunisation should be considered.

Statistical analysis

Statistical analyses were performed using the SPSS package version 10.0 (SPSS Inc., Chicago).

\section{Results}

Maternal characteristics

In 2001, a total of 1513 women gave birth to 1554 infants at the University Women's Hospital, Basel. Of these 1513 women, 699 (46\%) were Swiss and $812(54 \%)$ were of foreign nationality. We were unable to determine the nationality in two women. In 1387 (91.7\%) women, HBsAg testing was performed as part of antenatal care and in 116 women $(7.7 \%)$ screening was only performed at delivery. Ten women $(0.7 \%)$ did not undergo any screening at all. None of the children born to these ten women received immunoprophylaxis.

Of the 1503 screened women, $18(1.2 \% ; 95 \% \mathrm{CI}$ : 0.65-1.75) were $\mathrm{HBsAg}$ positive, including 2 of those $116(2 \%)$ screened during delivery. $\mathrm{HBeAg}$ status was tested in six (33\%) HBsAg positive women and one was found to be $\mathrm{HBeAg}$ positive. Of the $18 \mathrm{HBsAg}$ positive women, 5 were Swiss, 10 were Turkish and 3 came from former Yugoslavia with nationality dependent prevalence rates of $0.7 \%, 5.7 \%$ and $2.4 \%$, respectively. None of 77 Asian and 54 African women were HBsAg positive.

Immunoprophylaxis in exposed infants after delivery

A total of 19 infants were born to $18 \mathrm{HBsAg}$ positive mothers. One infant was lost to follow-up. Of the remaining 18 infants (11 girls, 7 boys), 17 received HBIG and HBV during hospital stay; $15(83 \%)$ infants received HBIG and $14(78 \%)$ received a first dose of HBV within $12 \mathrm{~h}$ after birth, respectively. In two cases, administration of HBIG and active immunisation was delayed by 24-48 h, including one child whose mother had only been screened during delivery. One premature infant 
(24th gestational week) was initially given HBIG and only at the age of 2 months was the first dose of HBV administered. In one newborn, the positive maternal HBsAg status was overlooked and therefore no immunoprophylaxis was administered. Unfortunately, acute hepatitis B infection (positive tests for HBsAg, Anti$\mathrm{HBc} \operatorname{IgM}$ and $-\mathrm{IgG}$ ) was diagnosed in this child at the age of 5 months and further serological testing at 1 and 2 years of age revealed persistence of $\mathrm{HBsAg}$, indicating chronic hepatitis B infection.

Information included in discharge letters

Discharge letters to the paediatricians of those 18 exposed children who had received hepatitis B immunoprophylaxis were analysed. Sixteen letters included information on the positive HBsAg status of the mother and the performed active and passive immunisation. Nine letters also included instructions to complete the active immunisation series after 1 and 6 months. No letter mentioned the recommendation of serological testing after completion of the immunisation series.

Completion of immunisation and serological follow-up

Of 17 exposed infants, $9(53 \%)$ had received a complete series of active immunisation, but only $2(12 \%)$ had been immunised strictly according to the recommended schedule at 0,1 and 6 months of age (Fig. 1). One child had received an additional fourth dose at 15 months of age.

In ten infants, where immunisation had been initiated according to the three-dose schedule, the second dose of HBV was delayed by $2-8$ months and in those who had already received the third dose, this was delayed by a further 1-5 months. In five infants immunised according to the four-dose schedule, the second and third dose of HBV were administered on time.

At the time of data analysis, eight infants had not yet received the full number of recommended doses and completion was enforced by our communication with the respective paediatricians. Furthermore, 11 of 18 exposed infants were between 9 and 16 months of age and 4 of them had been fully immunised. In one child, serological testing had been performed by the paediatrician and serum specimens were obtained in further three infants on our initiative. Anti-Hbs antibody values were $\geq 100 \mathrm{mIU} / \mathrm{ml}$ in all four children.

\section{Discussion}

In the western world, morbidity and mortality of hepatitis B virus infection primarily results from chronic infection which occurs at highest risk $(90 \%)$ with infections acquired perinatally or early in the postnatal
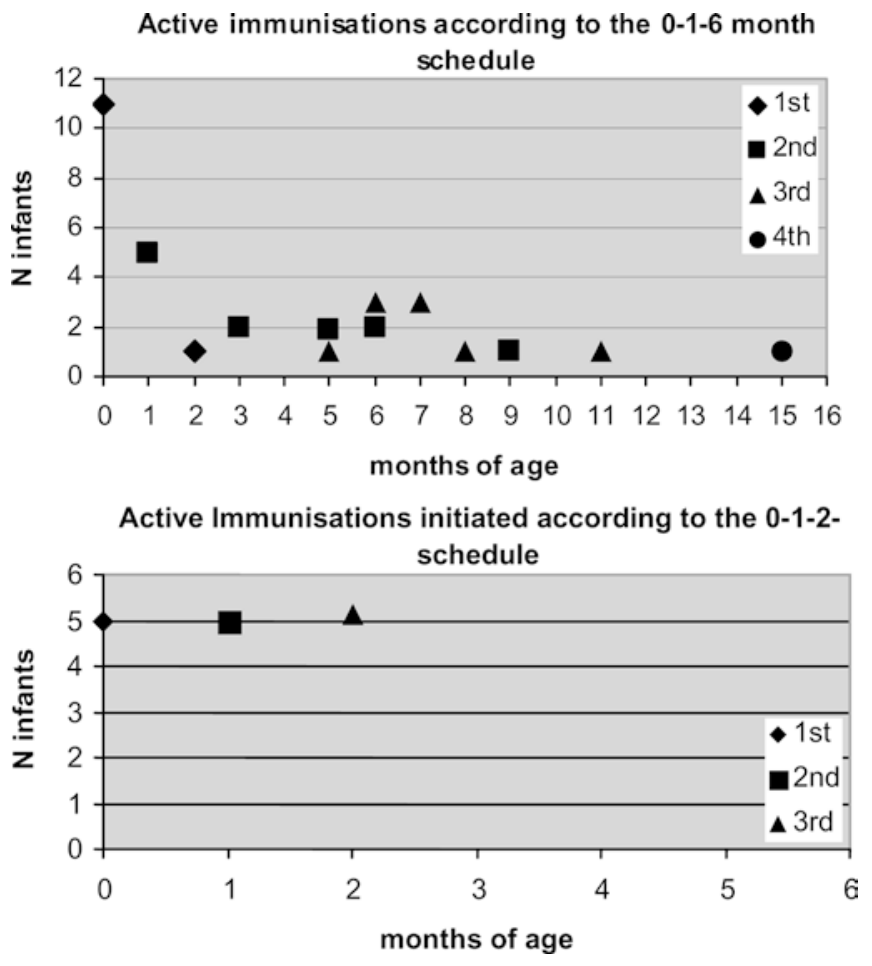

Fig. 1 Time points and doses of active immunisations in $\mathrm{HBsAg}$ exposed infants

period. In contrast, intra-uterine infections are rare. Therefore, screening of pregnant women for positive HBsAg followed by appropriate immunizations of infants, if needed, is crucial to avoid hepatitis B virus transmission $[4,10,16]$.

In an earlier investigation performed in Switzerland, the prevalence of chronic hepatitis B infection in pregnant women was $0.5 \%$ [12]. In this current study in a predominantly urban area of Switzerland, $1.2 \%$ of pregnant women tested positive for HBsAg.

Surprisingly, but probably due to low numbers and/ or selection, none of 131 pregnant women originating from Africa or Asia tested positive despite the fact that hepatitis B prevalence rates are known to be high in these areas.

While screening of pregnant women for HBsAg was excellent in this investigation, compliance with immunoprophylaxis recommended in their offspring in the case of a positive result was concerning and put children at unnecessary risk for acquisition of infection. Of particular concern, one exposed child was found to be chronically infected due to negligence of official recommendations which prompted counselling of the family and notification of the hospital's malpractice insurance.

Approximately $8 \%$ of women admitted for delivery had no previous HBsAg testing performed. Although this rate is favourable compared with that from a study in Germany, where $29 \%$ of the women had an unknown HBsAg status at birth [9], the lack of specific recommendations under such circumstances in Switzerland creates problems in clinical management. Other 
countries, like Germany, recommend a first dose of active immunisation under such circumstances, followed by passive immunisation up to 7 days after birth in case the mother's HBsAg test turns out positive [10]. The American Academy of Pediatrics has published similar recommendations [1] and in our opinion this should also be considered in Switzerland. Of note, breast-feeding is not a risk for hepatitis B infection in adequately immunised infants.

A further problem was identified in a preterm infant, where active immunisation was delayed by mistake. Data from recent studies do in fact recommend immediate immunisation of exposed infants regardless of gestational age and comparable immune responses have been documented in preterm and full-term infants [4].

Finally, compliance with completion of the HBV immunisation series and further serological testing was not optimal in this investigation. Studies performed in other countries revealed similar findings with good compliance with administration of the first dose of HBV while infants are still in hospital, whereas only $65 \%-$ $91 \%$ of exposed infants received their second and third doses $[5,8,14,15]$. This clearly requires improvement, which could easily be implemented by verbal and written instructions to both the parents and the child's paediatrician in private practice.

Based on the findings in this study, our institution has optimised standard procedures and adequate consequences have been taken. Other institutions may feel encouraged to ensure that appropriate measurements for prophylaxis of perinatal hepatitis B virus transmission are being performed.

Acknowledgement We are grateful to PD Dr. Irene Hösli and colleagues at the University Woman's Hospital in Basel for their excellent support.

\section{References}

1. American Academy of Pediatrics (1997) Hepatitis B. In: Peter $G$ (ed) Red book. Report of the Committee on Infectious Diseases 1997, 24th edn. Elk Grove Village, p 257
2. Beasley RP, Hwang LY, Lee GC, Lan CC, Roan CH, Huang FY (1983) Prevention of perinatally transmitted hepatitis B virus infections with hepatitis B immune globulin and hepatitis B vaccine. Lancet 2: 1099-1102

3. Bundesamt für Gesundheit (BAG) (1997) Empfehlungen zur Hepatitis-B-Impfung, Supplementum II, Stand Dezember 1997

4. Golebiowska M, Kardas-Sobantka D, Chlebna-Sokol D, Sabanty W (1999) Hepatitis B vaccination in preterm infants. Eur J Pediatr 158: 293-297

5. Grosheide PM, Klokman-Houweling JM, Conyn-van Spaendonck MAE, National Hepatitis B Steering Committee (1995) Programme for preventing perinatal hepatitis B infection through screening of pregnant women and immunization of infants of infected mothers in the Netherlands, 1989-92. BMJ 311: $1200-1202$

6. Marion SA, Pastore MT, Pi DW, Mathias RG (1994) Longterm follow-up of hepatitis $B$ vaccine in infants of carrier mothers. Am J Epidemiol 140: 734-746

7. Mele A, Tancredi F, Romano L, Giuseppone A, Colucci M, Sangiuolo A, Lecce R, Adamo B, Tosti ME, Taliani G, Zanetti AR (2001) Effectiveness of hepatitis B vaccination in babies born to hepatitis B surface antigen-positive mothers in Italy. J Infect Dis 184: 905-908

8. Mortimer PP, Miller E (1997) Commentary: antenatal screening and targeting should be sufficient in some countries. BMJ 314: 1036-1037

9. Parasher K, Bartsch M, Gstetttenbauer M, Entezami M, Versmold H, Stück B (2001) Generelles Hepatitis-B-Screening in der Schwangerschaft. Dt Ärzteblatt 98: A 329-331 (Heft 6)

10. Robert Koch-Institut (2001) Impfempfehlungen der Ständigen Impfkommision (STIKO) am Robert Koch-Institut. Epidemiol Bull 28: 203-218

11. Roure C (1995) Overview of epidemiology and disease burden of hepatitis B in the European region. Vaccine 13[Suppl 1]: 1821

12. Sidiropoulos D, Wegmann G, Bütler R, Von Muralt G (1988) Hepatitis-B-Screening in der Spätschwangerschaft und Resultate der Immunisierung bei den Neugeborenen. Schweiz Med Wschr 118: 309-312

13. Steven CE, Beasley RP, Tsui J, Lee WC (1975) Vertical transmission of hepatitis B antigen in Taiwan. N Engl J Med 292: 771-774

14. Van Steenbergen JE, Leentvaar-Kuijpers A, Baayen D, Dukers HTM, Van Doornum GJJ, Van den Hoek JAR, Coutinho RA (2002) Evaluation of the hepatitis B antenatal screening and neonatal immunization program in Amsterdam, 1993-1998. Vaccine 20: 7-11

15. Wallis DE, Boxall EH (1999) Immunization of infants at risk of perinatal transmission of hepatitis $\mathrm{B}$ : retrospective audit of vaccine uptake. BMJ 318: 1112-1113

16. Wu JC, Tong MJ, Hwang B, Lee SD, Hu MM (1987) Primary hepatocellular carcinoma and hepatitis B infection during childhood. Hepatology 7: 46-48 